\title{
Automatic limit switch calibrator for control valve at steam turbine of a geothermal power plant
}

\author{
Prisma Megantoro', Abdul Latif ${ }^{2}$, Brahmantya Aji Pramudita ${ }^{3}$, P. Vigneshwaran ${ }^{4}$ \\ ${ }^{1}$ Faculty of Advanced Technology and Multidisciplinary, Universitas Airlangga, Indonesia \\ ${ }^{2}$ Electrical Engineering, Universitas Muhammadiyah Yogyakarta, Indonesia \\ ${ }^{3}$ School of Electrical Engineering, Telkom University, Indonesia \\ ${ }^{4}$ Department of CSE, SRM Institute of Science \& Technology, Kattankulathur, Chennai, India
}

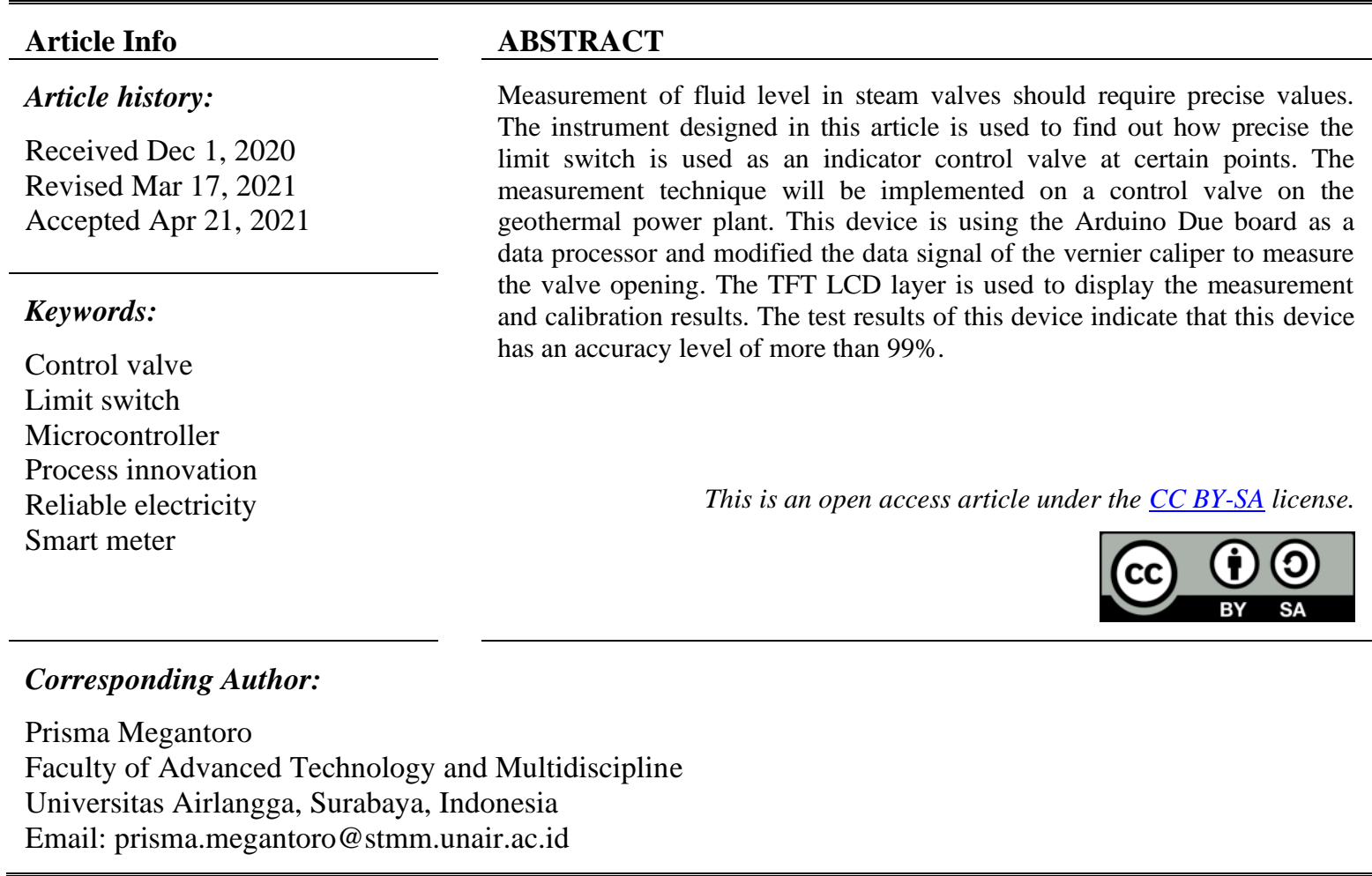

\section{INTRODUCTION}

In the era of the industrial revolution 4.0, an automation system has always been a mainstay in every production unit. The productivity of this machine supports the success of the system in meeting market demand for goods and services. Moreover, in the electricity production unit, or what is commonly referred to as the electricity generation unit. Where the need for electricity is also the main support in human life. The fulfillment of electricity is vital so that humans in an area can carry out their daily activities.

The electricity production must be maintained to keep the supply so that the customer needs can be provided steadily. Therefore, the electricity generation unit system must have a good design. The system can handle much information to control the process. The control system process can be done by automatic and manually. The automatics system works based on the information so that it can control the desired actuator without human intervention. However, the manual system needs human intervention. The advantage of an automatics system can be utilized in many applications, such as controlling motor [1], [2], turbine [3], valve [4], [5]. Thus, the automatics system can be used in power plants.

Geothermal power plants are built around plate tectonics where high-temperature geothermal sources are available near the surface [6]-[8]. Developments and refinements in drilling and extraction technology have expanded the range of geothermal power plant construction from nearby tectonic plates [9], [10]. The thermal efficiency of geothermal power plants tends to be low because the fluid is at a lower temperature compared to steam or boiling water [11], [12]. 
In a geothermal generation system, there must be a steam turbine unit to produce electricity. The steam turbine is an initial drive that converts potential energy into kinetic energy. Then the kinetic energy is converted into mechanical energy to rotate a turbine shaft. A control valve on the steam turbine is also installed which functions to rule the machine's final power production and rotational speed [13]-[15]. The control valve is mostly operated at a medium or large opening ratio with an optimized pressure drop. Peng et al. [16] conducted a study to observe the flow behavior for a steam turbine control valve. Research has also been conducted by Shaoshih et al to analyze single turbine valve closure [17] and Ling et al. [18] who develop an incipient fault diagnosis of the limit switch. Research to determine the control valve nonlinear characteristic using MARS was conducted by Halimi et al. [19]. Specifically, Bryan et al. [20] studied for exploiting nonsmooth fold bifurcations in the design of ultra-fast and robust, resettable, electromechanical limit switches.

This study designed an automation device to calibrate the limit switch of a control valve opening in a steam turbine. The device that uses the Arduino Due board is installed on one of the control valves which is the main line of fluid from the steam turbine. This device shows 10 aperture values at each limit switch. The distance of the control valve opening is measured using a vernier caliper mounted directly on the valve. The data from this caliper distance reading is sent to the microcontroller board for further processing and display on the LCD. Each limit switch that is on or off will be detected and its distance value stored. This is done to find out which distance each limit switch is on or off. The consideration of using this microcontroller board is its ability to support real-time automation systems [21]-[41]. This Arduino board uses an ARM-Cortex M3 CPU core which has a 32-bit ARM core microcontroller [42]-[44].

\section{PROCEDURE}

This research is divided into two parts, namely hardware consisting of a digital vernier caliper and a microcontroller board interface circuit and firmware as a program that runs the performance of the microcontroller board. The research of this article uses some calibration method carried out from RTD [45]-[47].

\subsection{System design}

A digital vernier caliper is used to detect the distance to the control valve opening. Figure 1 showed the block diagram of the digital vernier caliper device. The 10 limit switches uses to detect fluid levels. The aperture distance data is sent to the Arduino Due board. The on/off status of each limit switch is also detected and processed by Arduino Due. The data is processed then displayed on the TFT LCD device for real-time observation for the operator in the field.

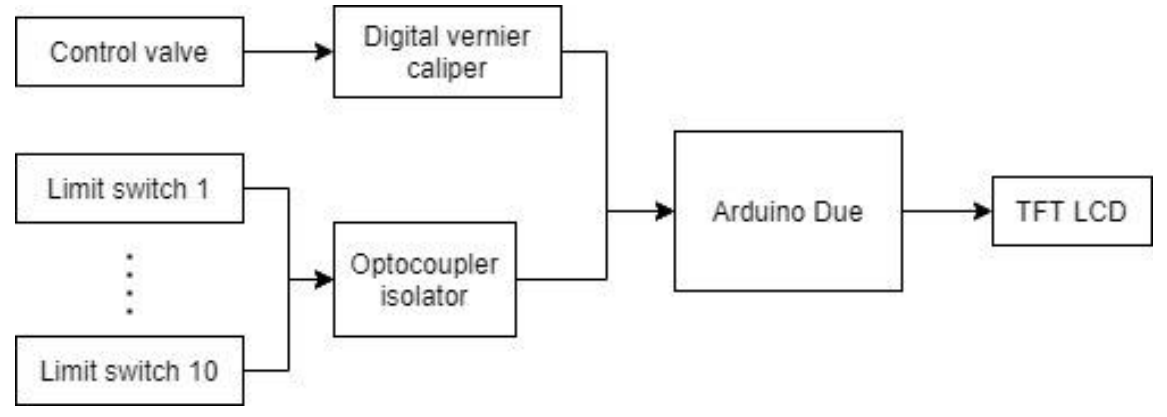

Figure 1. System block diagram

\subsection{Hardware design}

The schematic diagram showed in Figure 2 is the hardware design of the digital vernier caliper device. This device is supplied with a $24 \mathrm{~V} / 5 \mathrm{~A}$ adapter. The selection of this adapter specification follows the field equipment specifications commonly used at the site plant. Arduino Due with a SAM3X8E 32BIT ARM Cortex-M3 CPU is used as a data processor. Measuring valve distance is done by placing a digital vernier caliper onto the valve. This caliper has digital output data. There are 2 pinouts, namely $\mathrm{D}+$ for clock output, and D- for measurement data in the form of high and low digital signals. This digital caliper power is supplied by the $5 \mathrm{~V}$ pin of the Arduino Due board. There are 10 limit switches which are also supplied with $24 \mathrm{~V}$ voltage from the adapter. The detection of each limit switch is carried out by using a DSR-IR4P optocoupler isolator circuit which has an input voltage of $24 \mathrm{~V}$ and an output voltage of $5 \mathrm{~V}$. This optocoupler isolator module has 4 channels, so it takes 3 modules to meet the detected limit switch. The use of this isolator is intended to secure the pins on the microcontroller board circuit from the shock effect coming from the main power supply. 


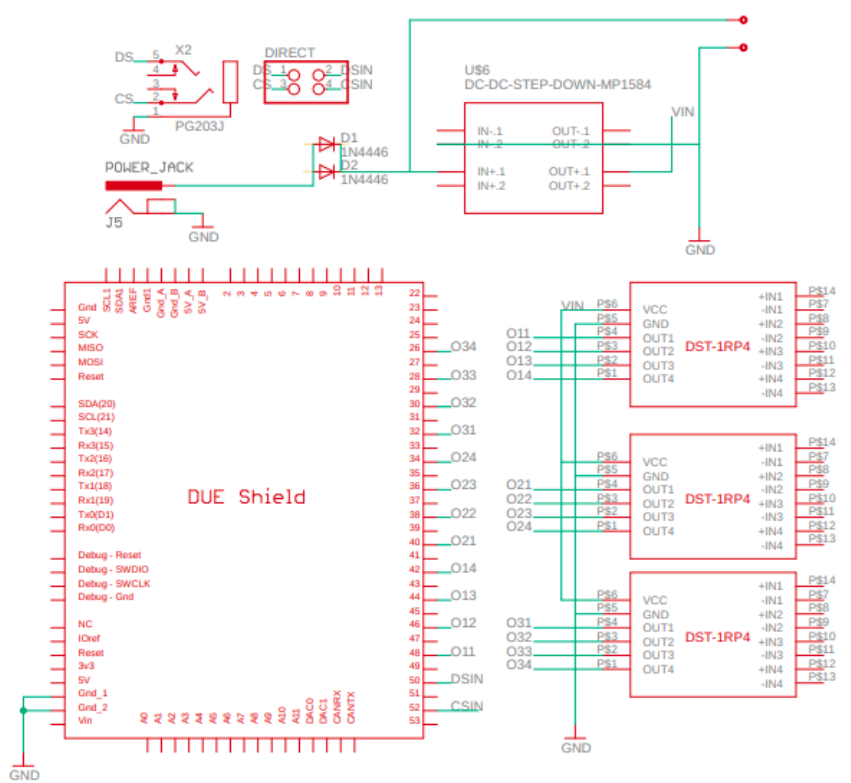

Figure 2. Schematic diagram of the device

\subsection{Firmware design}

Firmware is created as a hardware workflow execution program which is showed in Figure 3 . This program is made on the Arduino IDE platform. This program uses the interrupt on the Timer3 feature to read the distance data from the digital caliper and detect the on/off status of each limit switch. While the main program is used to display the user interface (UI) which contains information on distance values and limit switch status.

The program starts with the initialization of libraries, variables, pins, interrupt programs, and other subprograms. The main program will start when the program detects a normal digital signal from the caliper, or you could say the caliper is connected. Then start the decoding of digital data from the caliper to find out the distance value.

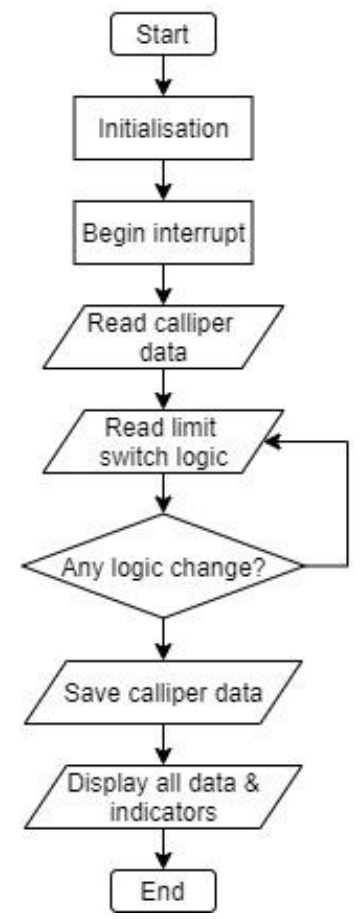

Figure 3. System workflow

Automatic limit switch calibrator for control valve at steam turbine of a geothermal... (Prisma Megantoro) 
After that is the arrangement of the UI display that is displayed on the TFT LCD. Each distance data and limit switch status will be displayed in real-time. For every logical change that occurs at each limit switch, the distance value will be stored in the limit switch status concerned. Normally, this logic change occurs sequentially from the one to the tenth limit switch. If the limit switch is detected as off, the limit switch indicator will turn red. However, if the limit switch is detected, the indicator will turn green.

\section{RESEARCH METHOD}

This calibrator limit switch device is placed on a control valve. The digital caliper mouth is attached to the valve to determine the distance of the valve opening at each logical change of the tenth limit switch.

\subsection{Assembled hardware}

Modifications were made to the digital caliper both electrically and mechanically. The PCB on this digital caliper has 4 pinouts that can be used to read from an external device. These 4 pins consist of VCC, GND, D +, and D-. The four pinouts are connected to Arduino. For this connection, a 4-channel $3.5 \mathrm{~mm}$ female audio jack is made.

In Figure 4, mechanical modifications were also made so that the cable connection between the digital caliper and the Arduino Due can be robust and safe from shocks. A 3D printed connector holder is attached to the digital plastic caliper case. Figure 5 shows a view of the assembled main controller board. The PCB which contains the Arduino Due, step down, TFT LCD, and all the oscillator optocouplers are placed in a portable case. Such assembly is intended so that the device can be carried easily and can be placed near the measuring location safely.

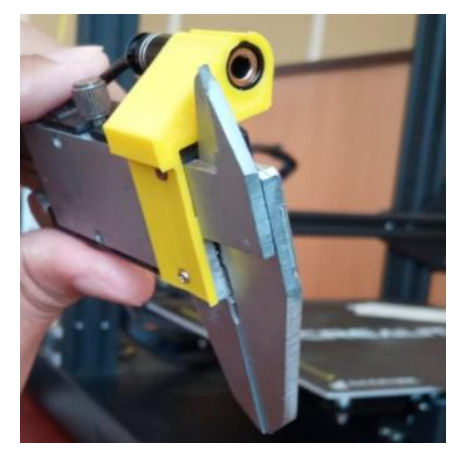

Figure 4. Output connector holder

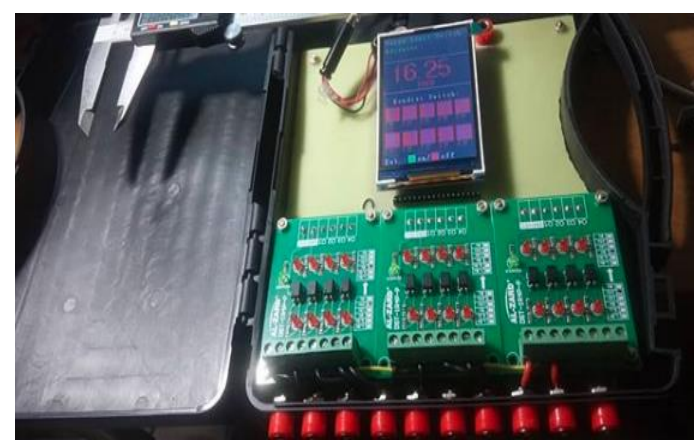

Figure 5. Visualisation of the main controller board

\subsection{UI display}

As mentioned in the previous section and Figure 6, this UI display contains the caliper reading distance and the on/off status of each limit switch. The distance value indicator shows the actual distance value in the field, this is for direct observation purposes. Meanwhile, the distance value in the on and off status on each limit switch indicator shows at what distance the limit switch has changed the status from off to on and vice versa. This is used to observe the accuracy of the limit switch in detecting the fluid level.

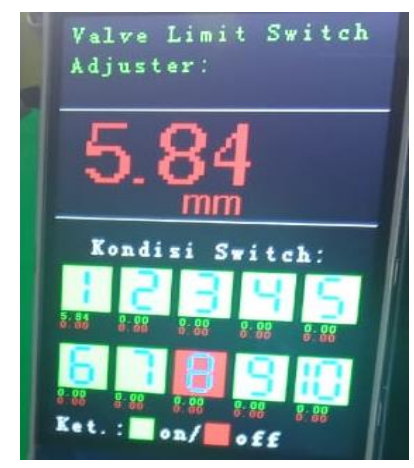

Figure 6. UI display of the system 


\section{RESULT AND DISCUSSION}

The measurement results are compared with standard measuring instruments to determine the level of accuracy and precision of the research device being made. The standard measuring instrument used for comparison is the manual or analog vernier caliper. The standard value was obtained from the reading of the standard caliper in millimeters. From Table 1 the test result shows that this device has more than $99 \%$ of accuracy.

$$
\begin{aligned}
& \text { Error }=\frac{\mid \text { Tested-Standart } \mid}{\text { Standart }} \\
& \text { Accuracy }=100-\text { Error }
\end{aligned}
$$

Table 1. Result of measurement test

\begin{tabular}{cccc}
\hline Tested $(\mathrm{mm})$ & Standart $(\mathrm{mm})$ & Error & Accuracy $(\%)$ \\
\hline 0.51 & 0.50 & 0.0200 & 99.980 \\
1.02 & 1.00 & 0.0200 & 99.980 \\
1.49 & 1.50 & 0.0067 & 99.993 \\
2.01 & 2.00 & 0.0050 & 99.995 \\
2.51 & 2.50 & 0.0040 & 99.996 \\
3.01 & 3.00 & 0.0033 & 99.997 \\
3.49 & 3.50 & 0.0029 & 99.997 \\
4.02 & 4.00 & 0.0050 & 99.995 \\
4.51 & 4.50 & 0.0022 & 99.998 \\
5.01 & 5.00 & 0.0020 & 99.998 \\
\hline
\end{tabular}

\section{CONCLUSION}

This study concludes that the calibrator limit switch device was successfully made with an accuracy rate of $99 \%$. The result of all measurements taken and displayed every 67 milliseconds, so the data of every limit switch opening and closing is actual. Otherwise, with a $24 \mathrm{VDC} / 5 \mathrm{~A}$ adapter for $220 \mathrm{VAC}$ electric port, this device is very reliable used in the field of geothermal power plant. The UI display makes it easy for users to observe the actual distance value and the logical changes of each limit switch installed on the control valve.

\section{REFERENCES}

[1] M. Khalifa, A. H. Amhedb, and M. Al Sharqawi, "Position Control of Real Time DC Motor Using LabVIEW," Journal of Robotics and Control (JRC), vol. 2, no. 5, pp. 342-348, 2021, doi: 10.18196/jrc.25104.

[2] D. Handaya and R. Fauziah, "Proportional-Integral-Derivative and Linear Quadratic Regulator Control of Direct Current Motor Position using Multi-Turn Based on LabView," Journal of Robotics and Control (JRC), vol. 2, no. 4, pp. 332-336, 2021, doi: 10.18196/jrc.24102.

[3] M. A. Shomad and F. R. Hidayat, "Vertical Blade Fiberglass Composite for Wind Turbine Power Plant Application," Journal of Robotics and Control (JRC), vol. 2, no. 3, pp. 148-152, 2021, doi: 10.18196/jrc.2369.

[4] Y. Irawan, A. Febriani, R. Wahyuni, and Y. Devis, "Water Quality Measurement and Filtering Tools Using Arduino Uno, PH Sensor and TDS Meter Sensor," Journal of Robotics and Control (JRC), vol. 2, no. 5, pp. 357-362, 2021, doi: 10.18196/jrc.25107.

[5] U. Rahmalisa, A. Febriani, and Y. Irawan, "Detector Leakage Gas Lpg Based On Telegram Notification Using Wemos D1 and Mq-6 Sensor," Journal of Robotics and Control (JRC), vol. 2, no. 4, pp. 287-291, 2021, doi: 10.18196/jrc.2493.

[6] Y. Wang, Y. Du, J. Wang, J. Zhao, S. Deng, and H. Yin, "Comparative life cycle assessment of geothermal power generation systems in China," Resour. Conserv. Recycl., vol. 155, no. November 2019, p. 104670, 2020, doi: 10.1016/j.resconrec.2019.104670.

[7] R. Parri, P. Basile, L. Favaro, T. Mazzoni, and S. Orlando, "The history of geothermal electric power plants on the Island of Ischia, Italy," Geothermics, vol. 89, no. June 2020, p. 101977, 2021, doi: 10.1016/j.geothermics.2020.101977.

[8] F. S. Tut Haklidır, "The importance of long-term well management in geothermal power systems using fuzzy control: A Western Anatolia (Turkey) case study,” Energy, vol. 213, 2020, doi: 10.1016/j.energy.2020.118817.

[9] F. Meng, X. Liang, C. Xiao, and G. Wang, "Geothermal resource potential assessment utilizing GIS-based multi criteria decision analysis method," Geothermics, vol. 89, no. June 2020, p. 101969, 2021, doi: 10.1016/j.geothermics.2020.101969.

[10] S. Yamanlar, E. D. Korkmaz, and U. Serpen, "Assessment of geothermal power potential in Buyuk Menderes Basin, Turkey," Geothermics, vol. 88, no. May, p. 101912, 2020, doi: 10.1016/j.geothermics.2020.101912.

[11] F. Taghizadeh-Hesary et al., "Role of energy finance in geothermal power development in Japan," Int. Rev. Econ. Financ., vol. 70, no. June, pp. 398-412, 2020, doi: 10.1016/j.iref.2020.06.011. 
[12] L. X. Zhang, M. Y. Pang, J. Han, Y. Y. Li, and C. B. Wang, "Geothermal power in China: Development and performance evaluation," Renew. Sustain. Energy Rev., vol. 116, no. February, 2019, doi: 10.1016/j.rser.2019.109431.

[13] M. Pondini, A. Signorini, and V. Colla, "Steam Turbine Control Valve and Actuation System Modeling for Dynamics Analysis,” Energy Procedia, vol. 105, pp. 1651-1656, 2017, doi: 10.1016/j.egypro.2017.03.539.

[14] M. Pondini, V. Colla, and A. Signorini, "Models of control valve and actuation system for dynamics analysis of steam turbines," Appl. Energy, vol. 207, pp. 208-217, 2017, doi: 10.1016/j.apenergy.2017.05.117.

[15] L. Fang, J. Wang, and X. Tan, "Analysis and Compensation of Oscillations Induced by Control Valve Stiction," IEEE/ASME Trans. Mechatronics, vol. 21, no. 6, pp. 2773-2783, 2016, doi: 10.1109/TMECH.2016.2559510.

[16] P. Wang and Y. Liu, "Unsteady flow behavior of a steam turbine control valve in the choked condition: Field measurement, detached eddy simulation and acoustic modal analysis," Appl. Therm. Eng., vol. 117, pp. 725-739, 2017, doi: 10.1016/j.applthermaleng.2017.02.087.

[17] S. Ma, Y. Yuann, and C. Shih, "The transient analysis of single turbine control valve closure for Lungmen ABWR,” Ann. Nucl. Energy, vol. 47, pp. 173-181, 2012, doi: 10.1016/j.anucene.2012.04.007.

[18] L. Wang, J. Pan, Y. Gao, B. Wang, K. Hong, and X. Chen, "Incipient fault diagnosis of limit switch based on a ARMA model," Meas. J. Int. Meas. Confed., vol. 135, pp. 473-480, 2019, doi: 10.1016/j.measurement.2018.11.080.

[19] B. Halimi and K. Y. Suh, "Engineering nonlinearity characteristic compensation for commercial steam turbine control valve using linked MARS code and Matlab Simulink," Nucl. Eng. Des., vol. 243, pp. 360-370, 2012, doi: 10.1016/j.nucengdes.2011.12.014.

[20] B. Wilcox and H. Dankowicz, "Limit-switch sensor functionality based on discontinuity-induced nonlinearities," $J$. Comput. Nonlinear Dyn., vol. 6, no. 3, pp. 1-8, 2011, doi: 10.1115/1.4002686.

[21] Y. Irawan, R. Wahyuni, and H. Herianto, "Morse Code Receiver On Invisible Light Using Background Subtraction Method," Journal of Robotics and Control (JRC), vol. 2, no. 4, pp. 283-286, 2021, doi: 10.18196/jrc.2492.

[22] S. Purwanti, A. Febriani, M. Mardeni, and Y. Irawan, "Temperature Monitoring System for Egg Incubators Using Raspberry Pi3 Based on Internet of Things (IoT)," Journal of Robotics and Control (JRC), vol. 2, no. 5, pp. 349-352, 2021, doi: 10.18196/jrc.25105.

[23] Y. Irawan, M. Muhardi, R. Ordila, and R. Diandra, "Automatic Floor Cleaning Robot Using Arduino and Ultrasonic Sensor,” Journal of Robotics and Control (JRC), vol. 2, no. 4, pp. 4-7, 2021, doi: 10.18196/jrc.2485.

[24] S. Widadi, S. A. B. Munir, N. Shahu, I. Ahmad, and I. Al Barazanchi, "Automatic Wireless Nurse Caller," Journal of Robotics and Control (JRC), vol. 2, no. 5, pp. 380-384, 2021, doi: 10.18196/jrc.25111.

[25] M. V. S. Rao and M. Shivakumar, "IR Based Auto-Recharging System for Autonomous Mobile Robot," Journal of Robotics and Control (JRC), vol. 2, no. 4, pp. 244-251, 2021, doi: 10.18196/jrc.2486.

[26] R. Perkasa, R. Wahyuni, R. Melyanti, H. Herianto, and Y. Irawan, "Light Control Using Human Body Temperature Based on Arduino Uno and PIR (Passive Infrared Receiver) Sensor," Journal of Robotics and Control (JRC), vol. 2, no. 4, pp. 307-310, 2021, doi: 10.18196/jrc.2497.

[27] P. K. Gayen and A. Sadhukhan, "Optimized Harmonic Reduction PWM based Control Technique for Three-Phase quasi Z-Source Inverter," Journal of Robotics and Control (JRC), vol. 2, no. 4, pp. 258-264, 2021, doi: 10.18196/jrc.2488.

[28] A. Latif, H. A. Widodo, R. A. Atmoko, T. N. Phong, and E. T. Helmy, "Temperature and Humidity Controlling System for Baby Incubator," Journal of Robotics and Control (JRC), vol. 2, no. 3, pp. 190-193, 2021, doi: $10.18196 /$ jrc.2376.

[29] D. U. Rijalusalam and I. Iswanto, "Implementation Kinematics Modeling and Odometry of Four Omni Wheel Mobile Robot on The Trajectory Planning and Motion Control Based Microcontroller," Journal of Robotics and Control (JRC), vol. 2, no. 5, pp. 448-455, 2021, doi: 10.18196/jrc.25121.

[30] R. T. Yunardi, D. Arifianto, F. Bachtiar, and J. I. Prananingrum, "Holonomic Implementation of Three Wheels Omnidirectional Mobile Robot using DC Motors," Journal of Robotics and Control (JRC), vol. 2, no. 2, pp. 65-71, 2021, doi: 10.18196/jrc.2254

[31] K. Purwanto, Iswanto, T. K. Hariadi, and M. Y. Muhtar, "Microcontroller-based RFID, GSM and GPS for motorcycle security system," International Journal of Advanced Computer Science and Applications, vol. 10, no. 3, pp. 447-451, 2019.

[32] Iswanto, J. Syaftriadi, A. Nur, N. Chamim, R. O. Wiyagi, and R. Syahputra, "LED and Servo Motor Control Via Bluetooth Based on Android Applications," International Journal of Recent Technology and Engineering (IJRTE), vol. 8, no. 2, pp. 6227-6231, 2019, doi: 10.35940/ijrte.B3264.078219.

[33] Iswanto, S. Suripto, F. Mujahid, K. T. Putra, N. P. Apriyanto, and Y. Apriani, "Energy Harvesting on Footsteps Using Piezoelectric based on Circuit LCT3588 and Boost up Converter," International Journal of Electrical and Computer Engineering (IJECE), vol. 8, no. 6, pp. 4104-4110, 2018, doi: 10.11591/ijece.v8i6.pp4104-4110.

[34] I. Iswanto, W. S. Agustiningsih, F. Mujaahid, R. Rohmansyah, and A. Budiman, "Accumulator Charging Control with Piezoelectric Based on Fuzzy Algorithm Scheduling," TELKOMNIKA (Telecommunication Computing Electronics, and Control), vol. 16, no. 2, pp. 635-640, 2018, doi: 10.12928/TELKOMNIKA.v16i2.7067.

[35] A. N. N. Chamim, M. Heru Gustaman, N. M. Raharja, and I. Iswanto, "Uninterruptable Power Supply based on Switching Regulator and Modified Sine Wave," International Journal of Electrical and Computer Engineering (IJECE), vol. 7, no. 3, pp. 1161-1170, 2017, doi: 10.11591/ijece.v7i3.pp1161-1170.

[36] A. N. N. Chamim, D. Ahmadi, and Iswanto, "Atmega16 Implementation As Indicators Of Maximum Speed," International Journal of Applied Engineering Research, vol. 11, no. 15, pp. 8432-8435, 2016. 
[37] I. Iswanto, K. Purwanto, W. Hastuti, A. Prabowo, and M. Y. Mustar, "Smart Smoking Area based on Fuzzy Decision Tree Algorithm," International Journal of Advanced Computer Science and Applications, vol. 10, no. 6, pp. 500-504, 2019.

[38] A. N. N. Chamim, M. E. Fawzi, I. Iswanto, R. O. Wiyagi, and R. Syahputra, "Control of Wheeled Robots with Bluetooth-Based Smartphones," International Journal of Recent Technology and Engineering (IJRTE), vol. 8, no. 2, pp. 6244-6247, 2019, doi: 10.35940/ijrte.B3352.078219.

[39] A. Maarif, S. Iskandar, and I. Iswanto, "New Design of Line Maze Solving Robot with Speed Controller and Short Path Finder Algorithm," International Review of Automatic Control (IREACO), vol. 12, no. 3, p. 154, 2019, doi: 10.15866/ireaco.v12i3.16501

[40] D. Hardiyanto, I. Iswanto, D. A. Sartika, and M. Rojali, "Pedestrian Crossing Safety System at Traffic Lights based on Decision Tree Algorithm," International Journal of Advanced Computer Science and Applications, vol. 10, no. 8, pp. 375-379, 2019.

[41] A. Latif, A. Z. Arfianto, H. A. Widodo, R. Rahim, and E. T.Helmy, "Motor DC PID System Regulator for Mini Conveyor Drive Based-on Matlab," Journal of Robotics and Control (JRC), vol. 1, no. 6, pp. 185-190, 2020, doi: 10.18196/jrc.1636.

[42] N. H. Wijaya, D. F. Novela, N. Shahu, and M. U. Sattar, "Arduino-based Mini Shaker for Automatic Chemical Solution Mixer," Journal of Robotics and Control (JRC), vol. 1, no. 6, pp. 220-223, 2020, doi: 10.18196/jrc.1641.

[43] Z. Dzulfikri, N. Nuryanti, and Y. Erdani, "Design and Implementation of Artificial Neural Networks to Predict Wind Directions on Controlling Yaw of Wind Turbine Prototype," Journal of Robotics and Control (JRC), vol. 1, no. 1, pp. 20-26, 2020, doi: 10.18196/jrc.1105.

[44] I. Prasojo, A. Maseleno, O. Tanane, and N. Shahu, "Design of Automatic Watering System Based on Arduino," Journal of Robotics and Control (JRC), vol. 1, no. 2, pp. 55-58, 2020, doi: 10.18196/jrc.1212.

[45] A. O. Ellazar, M. P. Sejera, and G. V. Magwili, "Implementation of checkers in tenney temperature chamber and thunder humidity generator for calibration failure detection and process time reduction," AIP Conference Proceedings, vol. 2045, no. 1, p. 020077, 2018, doi: 10.1063/1.5080890.

[46] N. Hambali, S. Saat, M. A. Ahmad, M. S. Ramli, and M. A. Ishak, "Computer-based system for calibration of temperature transmitter using RTD," 2010 3rd International Conference on Information Management, Innovation Management and Industrial Engineering, Kunming, China, 2010, pp. 332-336, doi: 10.1109/ICIII.2010.400.

[47] K. V. Santhosh and B. K. Roy, "An adaptive calibration circuit for RTD using optimized ANN," 2013 7th International Conference on Intelligent Systems and Control (ISCO), Coimbatore, India, 2013, pp. 49-54, doi: 10.1109/ISCO.2013.6481121.

\section{BIOGRAPHIES OF AUTHORS}
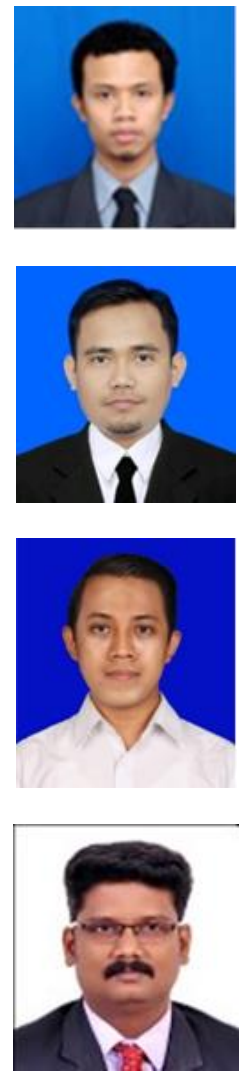

Prisma Megantoro is a lecturer in Electrical Engineering, School of Advanced Technology, and Multidiscipline, Universitas Airlangga since 2020. He received a bachelor's degree and master's degree from Universitas Gadjah Mada, Yogyakarta, Indonesia in 2014 and 2018. His current research is focused on solar photovoltaic technology, embedded system, and the internet of things.

Abdul Latif is an entrepreneur and student. He obtained a Diploma Three degree at the Yogyakarta Muhammadiyah Polytechnic in 2013 and a bachelor's degree from the Respati Yogyakarta University, Indonesia in 2017, is currently studying for a master's degree at the Sultan Agung University Semarang. His research is currently focused on medical equipment.

Brahmantya Aji Pramudita is a lecturer in Electrical Engineering, School of Electrical Engineering, Telkom University since 2020. He received a bachelor's degree and master's degree from Universitas Gadjah Mada, Yogyakarta, Indonesia in 2015 and 2018. His research interest includes instrumentation, digital signal processing, and biomedical engineering.

P. Vigneshwaran has obtained his Doctoral Degree in Anna University Chennai in 2016 and Master of Engineering under Anna University Chennai in June 2005. He is having 18.4 years of experience and specialization in Cybersecurity. Presently, He is working as Associate Professor at the SRM Institute of Science and Technology, Chennai. He has published more than 18 papers in various international journals and 5 in International Conferences. His area of interest includes Security, Routing, and Intelligent Data Analysis. 